\title{
"NOS CAMINHOS DA GEOGRAFIA": PROPOSTA DE ATIVIDADE PRÁTICA, UM DESAFIO PARA O PROJETO PEDAGÓGICO DO CURSO DE GEOGRAFIA DA UERN / CAMPUS DE PAU DOS FERROS, RN
}

\author{
Josué Alencar Bezerra ${ }^{1}$ \\ Cícero Nilton Moreira da Silva²
}

RESUMO: O presente trabalho relata a experiência da atividade prática "Nos caminhos da Geografia", componente curricular obrigatório do Curso de Geografia do Campus Avançado "Prof a Maria Elisa de Albuquerque Maia" (CAMEAM), da Universidade do Estado do Rio Grande do Norte (UERN). A partir da concepção do Projeto Pedagógico do Curso, elaboramos a proposta de trabalho que desenvolvemos com alunos de diferentes níveis da graduação. Visando gerar respostas à inquietação sobre o papel do profissional de Geografia em lidar com algumas situações postas na atualidade, esta iniciativa tem base de fundamentação metodológica em algumas experiências extensionistas desenvolvidas no âmbito do curso. O projeto "Nos caminhos da Geografia" surge a partir da reflexão acerca da realidade socioespacial na qual o curso encontra-se inserido. O presente trabalho configura-se como um relato de experiência de um projeto de atividade prática. Portanto, apresentamos, na verdade, algumas considerações acerca da experiência vivenciada pelos professores orientadores do respectivo projeto.

PALAVRAS-CHAVE: Atividade prática. Caminhos da Geografia. Projeto pedagógico.

"The Geography Paths": a practice activity proposal, a challenge for a pedagogical project of Geography graduation at UERN / Campus de Pau dos Ferros, RN

\begin{abstract}
This study aims to develop an account of experience of practical activity "Nos Caminhos da Geografia" (The Geograph Paths), required curricular component of the Course of Geography Campus Advanced "Prof a Maria Elisa de Albuquerque Maia" (CAMEAM), Universidade do Estado do Rio Grande do Norte (UERN). Initially based on the Pedagogical Graduation Project conception, the proposed work has been elaborated with different levels of graduation students. In order to generate responses concerning the professional role of Geography in dealing with some nowadays situations, this proposal is based on methodological foundation in some experiments carried out under the extension course. The project "Nos Caminhos da Geografia" arises from the reflection around the sociospatial reality where the course is based on. This work is develop as an experience report based on a practicing project activity. Therefore, we present, in fact, some considerations about the living professors experience that guided the project.
\end{abstract}

KEYWORDS: Practice activity. The Geography Paths. Pedagogical project.

\footnotetext{
${ }^{1}$ Doutorando em Geografia pela Universidade Estadual do Ceará, professor do Departamento de Geografia da Universidade do Estado do Rio Grande do Norte (Campus de Pau dos Ferros) (josueabezerra@gmail.com.br).

${ }^{2}$ Doutor em Geografia pela Universidade Federal do Ceará, professor do Departamento de Geografia da Universidade do Estado do Rio Grande do Norte (Campus de Pau dos Ferros) (ciceronilton@yahoo.com.br). 


\section{INTRODUÇÃO}

A discussão que apresentamos nasceu de uma inquietação tida desde a construção do Projeto Pedagógico do Curso de Geografia do Campus Avançado "Prof ${ }^{a}$ Maria Elisa de Albuquerque Maia" (CAMEAM), da Universidade do Estado do Rio Grande do Norte (UERN), localizado na cidade de Pau dos Ferros-RN, no que se refere às atividades práticas como componente obrigatório do curso, trazendo a experiência da modalidade do projeto "Nos caminhos da Geografia".

Para este trabalho, desenvolvemos, inicialmente, uma reflexão sobre o papel do profissional de Geografia perante as mudanças socioeconômicas e culturais na produção do espaço contemporâneo. Tentamos pensar esse profissional como um intelectual importante na construção de mecanismos de formação, em uma perspectiva mais ampla, oportunizando o direito ao questionamento e ao pensar sobre a realidade atual.

Em seguida, realizamos uma exposição das experiências da "Atividade Curricular em Comunidade" (ACC), intitulada "Diálogos na Reforma Agrária" e do projeto de extensão "Leitura e Intervenção Comunitária no Bairro Riacho do Meio, Pau dos Ferros (RN)". As atividades extensionistas são espaços fundamentais de socialização e produção do conhecimento e de articulação entre a universidade e a sociedade, desenvolvidas no âmbito da Geografia.

Apresentaremos, também, a organização da oferta das atividades práticas como componente curricular obrigatório do curso em questão e as modalidades, com suas respectivas temáticas e metodologias. Teceremos, ainda, considerações sobre a proposta de trabalho "Nos caminhos da Geografia", apresentando a forma como esta modalidade é pensada e desenvolvida no curso de Geografia.

Por fim, teceremos algumas considerações acerca da experiência do projeto "Nos caminhos da Geografia" no curso, o contingente, as expectativas e possibilidades futuras na execução da atividade prática.

\section{A Geografia frente aos desafios contemporâneos}

As transformações técnico-científicas e culturais pelas quais o mundo vem passando atualmente têm proporcionado uma reflexão sobre o real papel do profissional de Geografia no acompanhamento do processo de produção do espaço, cada vez mais globalizante, desigual e contraditório. Quadro, este, gerado pela interdependência da ciência e da técnica, em todos os aspectos, na sociedade. A internacionalização da produção, a generalização do crédito e, principalmente, a revolução da informação, ligando instantaneamente os lugares, são fatores que cada vez mais interferem na vida social das pessoas.

Este fenômeno, como coloca Santos (2008), caracteriza o espaço como locus da exacerbação das especialidades produtivas. Além disso, aponta uma tensão crescente entre a localidade e a globalidade, assim como o fortalecimento da divisão territorial e da divisão social do trabalho. 
No Brasil, todas as áreas experimentam esse processo, tendo como principal característica o revigoramento do processo de urbanização, mesmo em níveis e formas diferentes, graças às diversas modalidades do impacto da modernização do território. Entretanto, devemos nos atentar para a lógica do modelo econômico atual, alimentado pela mídia e pelo consumo de massa.

Todas essas mudanças têm geradoum panorama no qual a nova relação espaço-tempo tem forte impacto na vida da sociedade de maneira a criar a necessidade de novas reflexões metodológicas para trabalhar estes conteúdos. Assim, para o profissional da Geografia, é exigida uma maior concentração a fim de entender e responder a tais transformações presentes no espaço geográfico da contemporaneidade.

Para tanto, os profissionais de Geografia necessitam rever os conceitos fundantes da ciência, como o de região, uma vez que estes não retratam mais as realidades e nem acompanham o ritmo dinâmico e complexo das transformações às quais o mundo vem passando. De acordo com Santos (2008, p. 102),

O que esmaeceu foi a nossa capacidade de reinterpretar e de reconhecer o espaço em suas divisões e recortes atuais, desafiando-nos a exercer plenamente aquela tarefa permanente dos intelectuais, isto é, a atualização dos conceitos é papel do intelectual atualizar os conceitos.

Diante deste quadro, o papel do intelectual e sua postura ética e política são colocados à prova. O especialista em Geografia necessita ficar entre os limites de uma neutralidade científica até a conduta profissional que envolve a causa abraçada pelo educador frente à situação posta em análise. Tem, portanto, o papel de possibilitar ao aluno construir mecanismos de formação numa perspectiva mais ampla, devendo oportunizar o direito ao questionamento e o pensar sobre a realidade nos espaços em que ela é produzida (PPC, 2007).

Esse quadro de mudança no mundo sugere uma cultura de consumo exacerbado, promovido, principalmente, pela mídia, gerando riscos decorrentes do crescimento material a qualquer custo, comprometendo, assim, o meio ambiente global. Entretanto, a concepção de desenvolvimento sustentável que o capital assume prioriza uma educação voltada para o mercado: repor e formar mão-de-obra que não questione as formas de produção, o consumo e a perda dos direitos sociais. Diante desse fato, qual o papel do profissional de Geografia?

Espera-se que este profissional seja formador de indivíduos críticos que busquem a justiça e a igualdade social, articulando valores éticos em relação ao trabalho e ao meio ambiente. No entanto, na educação, a Geografia, em geral, torna-se instrumento para a perpetuação do senso comum, instaurado e preconizado por uma classe dominante e que oprime. A adoção do livro didático caracteriza esta manifestação, mesmo que de forma inconsciente ou justificada, ou ainda pela aparente falta de opções de escolha, ou a escolha do material didático mais usado, sem razão ou fundamentação teórica pertinente.

O aprendizado do funcionamento dos aparatos técnico-científicos - com os quais os cidadãos convivem em seu dia-a-dia -, de forma crítica e reflexiva e em uma velocidade cada vez maior, é desafiador. Essa problemática perpassa a escolha dos caminhos para a implementação dessas ideias 
e da seleção dos conteúdos para o ensino. Assim, ensinar por meio da resolução de problemas, habituando os alunos a determinarem, por si próprios, respostas às questões que os inquietam, sejam elas escolares ou da vida cotidiana, ao invés de esperar uma resposta já pronta, resulta numa formação mais qualificada deste intelectual.

Torna-se importante a participação do aluno na determinação de situações-problema, uma vez que o que é desconhecido para alguns pode ser resolvido muito rapidamente por outros. $\mathrm{O}$ questionamento deverá ser uma situação diferente da que já se tenha trabalhado, mas que utilize técnicas e estratégias já aprendidas para a sua solução.

Na proposta de trabalho que estamos desenvolvendo no âmbito da Geografia, o professor adota a metodologia da resolução de problemas, na qual seu papel será de incentivador, facilitador e mediador das ideias apresentadas, de modo que estas sejam produtivas, levando os discentes a pensarem e a gerarem seus próprios conhecimentos, bem como a lidarem com qualquer situaçãoproblema na qual se encontrem.

Os processos e as práticas espaciais engendradas na região de abrangência do curso de Geografia do CAMEAM, fruto da forma como se realizam, historicamente, a ocupação e a formação desse território, demandam uma análise mediada pela atuação do ensino de Geografia, no sentido de compreender a evolução e a dinâmica socioespacial da região. Para tanto, algumas experiências metodológicas de extensão desenvolvidas, principalmente, na área em questão, servem como um ensaio que norteia nossa proposta de atividade prática.

\section{Experiências metodológicas de extensão}

A extensão universitária vem se afirmando, nos últimos anos, como espaço fundamental de socialização e produção do conhecimento e de articulação entre a universidade e a sociedade, razão pela qual tem se tornado um projeto social cada vez mais reconhecido institucionalmente na academia.

A Constituição Brasileira de 1988 estabelece, e a Lei nº 9.394/96 reafirma, a indissociabilidade entre as dimensões que constituem o tripé universitário. O pressuposto define que a educação superior deve, entre outras finalidades, "promover a extensão, aberta à participação da população, visando à difusão das conquistas e benefícios resultantes da criação cultural e da pesquisa científica e tecnológica geradas pela instituição" - Inciso VII do artigo 43 - e que "a educação superior abrangerá cursos e programas, entre os quais, os de extensão, abertos a candidatos de acordo com requisitos da instituição" - inciso IV do artigo 44 (BRASIL, 2008).

Consoante ao Plano Nacional de Extensão (1991-2001), a extensão universitária define-se como "prática acadêmica que interliga a Universidade nas suas atividades de ensino e pesquisa com as demandas da população". Tal concepção nasce de uma nova perspectiva de universidade: a multiplicidade para além da pesquisa e ensino, pautada na conscientização e na politização do conhecimento, possibilitando a formação profissional no caminho da qualificação, por meio do compromisso entre universidade e sociedade. A universidade, portanto, assume o papel e o desafio 
de promover processos de humanização das práticas dos sujeitos, em seus diversos contextos, sob a ótica da transformação social.

Neste contexto, o CAMEAM compreende, ao longo de sua história de mais de trinta anos de atuação, um conjunto de experiências no desenvolvimento de projetos e atividades de natureza extensionista. Nesse sentido, o curso de Geografia do CAMEAM/UERN, desde 2006, desenvolve projetos de extensão, no exercício da reflexão/ação acerca das problemáticas que envolvem a produção do espaço regional. Faz-se relevante destacar o contexto socioespacial em que está inserido o curso, no sentido de evidenciar a importância da extensão para a sua região de abrangência. Para tanto, relataremos duas experiências ocorridas no mesmo.

\section{Diálogos na Reforma Agrária}

O projeto "Diálogos na Reforma Agrária" configurou-se como uma Atividade Curricular em Comunidade (ACC), modalidade de atividade de extensão criada na UERN por meio da Resolução $n^{\text {o }}$ 027/2004 do CONSEPE de 21 de julho de 2004. Como componente curricular de natureza optativa, caracterizou-se pela interdisciplinaridade como condição essencial ao exercício da indissociabilidade com a pesquisa e o ensino.

O projeto foi desenvolvido pelo curso de graduação em Geografia do CAMEAM/UERN entre os semestres letivos 2006-1 e 2007-2, reunindo acadêmicos dos cursos de Geografia, Pedagogia, Economia, Enfermagem e Letras.

O Assentamento de Reforma Agrária Paraná foi o grupo comunitário com o qual o projeto desenvolveu ações. Localizado no município de Itaú-RN, a aproximadamente $58 \mathrm{~km}$ de Pau dos Ferros, o assentamento, criado pelo Instituto Nacional de Colonização e Reforma Agrária (INCRA), no ano de 1998, possui área de 960 hectares, espaço de vida para 30 famílias assentadas. O projeto de extensão teve como objetivos: a) fortalecer a articulação entre a universidade e a comunidade, voltando-se à compreensão da questão agrária na regioão do Alto Oeste Potiguar; b) relacionar teoria e prática na perspectiva da construção do conhecimento social crítico, por meio de uma metodologia participativa; c) estimular a participação política e o senso de coletividade para o desenvolvimento local.

O estímulo ao convívio entre os membros do projeto e os comunitários foi condição para a realização desta atividade que teve como aporte teórico-metodológico a utilização da Intervenção Participativa dos Atores (INPA), conforme Furtado e Furtado (2000). Os principais resultados observados foram: a interação e integração entre os atores envolvidos (comunitários, alunos e professores); a formulação de um Plano Básico de Atuação Interdisciplinar e a elaboração do resgate sócio-histórico da comunidade. 


\section{Leitura e intervenção comunitária no bairro Riacho do Meio}

O projeto de extensão "Leitura e Intervenção Comunitária no Bairro Riacho do Meio, Pau dos Ferros (RN)" teve como objetivos: a) promover a reflexão acerca da articulação universidadesociedade; b) impulsionar a consciência crítica e organizativa da comunidade, como condição para o enfrentamento das problemáticas socioespaciais na área em questão; c) exercitar a formação acerca de como trabalhar com o povo; d) refletir sobre a gestão comunitária do espaço urbano, na escala do bairro; d) criar uma agenda política de discussão e intervenção dos sujeitos sociais.

Neste sentido, o projeto viabilizou a interação de discentes e docentes do curso com os atores sociais do bairro, visando refletir sobre a produção e a gestão territorial urbana, bem como sobre a participação popular na construção de uma agenda política que defina objetivos, estratégias e prioridades para o fortalecimento das potencialidades locais.

Destaca-se como resultado significativo dessa ação a sensibilização e a mobilização do segmento jovem (notoriamente ativo e partícipe nas atividades e metodologias desenvolvidas), orientando os caminhos para a continuidade desta ação na perspectiva de estabelecer o protagonismo juvenil como norteador do processo de leitura e intervenção comunitária no bairro Riacho do Meio.

O motivo pelo qual nos reportamos à caracterização destes dois projetos vem no sentido de que a proposta metodológica que norteia as respectivas ações extensionistas corrobora com os objetivos tratados na formulação do projeto "Nos caminhos da Geografia".

\section{A atividade prática a partir do projeto pedagógico do curso de Geografia}

O Projeto Pedagógico do Curso de Geografia do CAMEAM/UERN foi idealizado a partir das concepções que mediam as ações do curso e da própria Geografia, que se produz e se consome no Alto Oeste do Rio Grande do Norte. Este importante instrumento norteador das atividades teve sua aprovação, no âmbito da universidade, em outubro de 2007, e preve as atividades práticas como componente curricular obrigatório, além das Disciplinas do Núcleo de Formação Básica, do Estágio Supervisionado e das Atividades Complementares.

A modalidade "Atividades Práticas", como prevê o artigo $2^{\circ}$ da Resolução CNE/CP 1, de 18 de fevereiro de 2002 (PPC, 2007), propõe a orientação de algumas ações inerentes à formação para a atividade docente como o aprimoramento em práticas investigativas; a elaboração e a execução de projetos de desenvolvimentos dos conteúdos curriculares; o uso de tecnologias da informação e da comunicação e de metodologias, estratégias e materiais de apoio inovadores; o desenvolvimento de hábitos de colaboração e de trabalho em equipe. Assim, buscamos propor um debate sobre as questões relacionadas à produção do espaço geográfico, tentando resgatar o papel social do geógrafo enquanto aquele que busca mapear a realidade na qual se insere, a partir de uma reflexão e intervenção no meio. 
As atividades práticas do curso de Geografia são ofertadas semestralmente, como preconiza o PPC (2007), a partir do primeiro período, pelos docentes e/ou profissionais convidados de outras unidades acadêmicas ou universidades/instituições de ensino superior. Para tanto, organizamos a matriz curricular do curso, observando e articulando as dimensões teóricas e práticas a serem contempladas, pensando as diferentes práticas numa perspectiva interdisciplinar.

As atividades devem ser abordadas com temáticas de natureza teórico-prática, imprescindíveis para a qualificação da formação docente, aprofundando saberes e conhecimentos científicos, bem como reforçando a importância da transversalidade e da interdisciplinaridade na construção de saberes (PPC, 2007).

O desenvolvimento das atividades práticas devem enfocar os procedimentos de observação e de reflexão. Isso porque visa à atuação em situações contextualizadas, executando registros e resolvendo algumas situações-problema que o profissional de Geografia poderá encontrar no campo de trabalho. Além disso, podem ser utilizadas algumas tecnologias da informação que incluam o computador e o vídeo, narrativas orais e escritas de professores, produções de alunos, situações simuladoras e estudo de casos.

As propostas de atividades práticas do curso de Geografia do CAMEAM/UERN permeiam o processo ensino-aprendizagem e a formação do profissional em Geografia. Sendo assim, atendem às orientações instituídas pelo Ministério da Educação(MEC) para todos os cursos de licenciatura do país.

Nessa perspectiva, são ofertados os seminários temáticos, que podem ser trabalhados por todas as áreas da Geografia, podendo apresentar conteúdos atualizados à medida que o corpo docente assim perceber necessários. Para esta modalidade, listamos a discussão sobre políticas públicas e gestão de recursos hídricos, sobre as quais o aluno deverá desenvolver uma pesquisa, tomando como ponto de partida a aplicação das leis (nacional e estadual) sobre Recursos Hídricos.

A modalidade "Planejamento Territorial e Desenvolvimento" objetiva orientar os alunos para a temática do planejamento territorial, visando à formação de consciência sociopolítica, econômica e ambiental, assim como mostrar diferentes formas da aplicação de políticas públicas com o objetivo do desenvolvimento local e regional.

A modalidade "Reforma Agrária, Movimentos Sociais e Assentamentos Rurais" propõe a reflexão acerca da problemática do espaço agrário brasileiro e, em particular, a região doAlto Oeste do Rio Grande do Norte. Nesse sentido, objetiva realizar estudos e atividades práticas em comunidades rurais da região.

O "Ensino de Geografia", por sua vez, visa discutir e produzir experiências vivenciadas, resultando na produção de métodos, estratégias, bem como materiais e instrumentos para o ensino da Geografia, considerando suas diferentes áreas temáticas.

A proposta de seminário com o tema "Cartografia e Novas Tecnologias" busca espacializar objetos naturais e antropizados da superfície terrestre com o advento das novas tecnologias, como o Sistema de Informações Geográficas. Este seminário visa à discussão, com os discentes, das principais ferramentas usadas para a construção de mapas, cartas e plantas e, 
principalmente, sua aplicação no ensino da Geografia nos níveis fundamental, médio e superior.

Temos ainda como modalidade de seminário os "Estudos Temáticos Integrados", que envolve temas como: "Conflitos internacionais"; "OBrasil esuas regiões"; "O espaçonorte-rio-grandense”, abordando os conteúdos de forma a privilegiar os conceitos de paisagem (natural e humanizada), lugar e território.

O seminário "Direito, cidadania e meio ambiente" tem como finalidade apresentar alguns conceitos básicos do Direito, essenciais ao exercício da cidadania. A prática da cidadania não está desvinculada da consideração e entendimento do meio ambiente. Nesse sentido, pretendemos abordar o referido tema. Um exemplo disto é a discussão acerca de meio ambiente e consumo.

Como outra modalidade, temos as "Oficinas Temáticas" que também integram as 400 horas de atividades práticas. O objetivo é qualificar os processos de reflexão e de produção de materiais e instrumentos didáticos que auxiliem no ensino de Geografia.

Os "Produtos Cartográficos" e "Representações Espaciais" constituem outras opções de oficinas. Nestas, os produtos cartográficos são construídos como maquetes, croquis, banners, que se configuram como representação das realidades espaciais da superfície terrestre. A partir daí, temos a compreensão de que a Cartografia, por meio de técnicas educacionais, quando bem aplicadas, pode se tornar uma excelente ferramenta de auxílio para o conhecimento geográfico, principalmente em uma região ainda tão carente de informações sobre a realidade local e regional, como o Alto Oeste do Rio Grande do Norte.

Temos, ainda, a oficina "Geografia e Arte" que busca utilizar novas abordagens no processo ensino-aprendizagem, destacando, atualmente, o uso das artes como forma de transmissão de conhecimentos geográficos. A atividade utiliza eixos norteadores, definidos processualmente e que são trabalhados em conjunto com produções cinematográficas (longas e curtas-metragens), produções literárias (brasileira e estrangeira) e composições musicais (nacionais), como instrumentos de base para a discussão e para as produções textuais (resenhas, paráfrases, paródias).

Outra modalidade de atividade são as "Práticas Laboratoriais" que tem como finalidade a utilização de técnicas de trabalho de campo e de laboratório nas várias disciplinas da referida área geográfica como a Geologia Geral, a Pedologia, Fundamentos de Climatologia, Biogeografia, Hidrografia e Fundamentos de Geomorfologia, Cartografia Geral, Cartografia Temática, Sensoriamento Remoto e Geoprocessamento e são realizadas nos laboratórios do Curso de Geografia.

Finalmente, ainda como modalidade de atividade prática, há o projeto "Nos caminhos da Geografia", que busca ampliar a relação entre universidade e sociedade. O projeto tem o intuito de gerar um maior conhecimento dos municípios do Alto Oeste do Rio Grande do Norte e de outras regiões do estado, além de alguns municípios do Ceará e da Paraíba, ou seja, da região que faz parte da área de abrangência do CAMEAM/UERN. Detalharemos melhor tal especialidade quando do relato da experiência que estamos desenvolvendo no Curso de Geografia no segundo semestre de 2012. 


\section{O projeto "Nos caminhos da Geografia"}

O projeto "Nos caminhos da Geografia" surge a partir das inquietações tratadas durante a discussão do marco referencial para a formulação do Projeto Pedagógico do Curso de Geografia do CAMEAM, quando da reflexão acerca da realidade socioespacial na qual o curso encontrase inserido. Assim, o grupo definiu como uma modalidade de atividade prática a construção da proposta de um projeto cujo intuito seria a ampliação da relação entre universidade e sociedade, ressaltando a importância das ações sob a égide dos seguintes princípios norteadores:

a. das práticas de observação, registro, análise e interpretação a partir das atividades de campo;

b. da oportunidade de abordagem dos saberes científico, técnico e popular por meio da aplicação de metodologia participativa, sob a perspectiva da Educação Popular;

c. da contribuição, para um maior conhecimento, dos municípios do Alto Oeste Potiguar e de outras regiões do Rio Grande do Norte, além de alguns municípios do Ceará e da Paraíba, ou seja, da região que faz parte da área de abrangência do Campus da UERN em Pau dos Ferros;

d. da ampliação dos espaços de diálogo e de interação com a sociedade, por meio do desenvolvimento de trabalhos, como palestras, minicursos e oficinas, juntamente com a população local;

e. do estabelecimento e/ou fortalecimento das parcerias (inter)institucionais, setores fundamentais para a concretização dessa dimensão prática: gestão pública, segmentos privados, órgãos públicos, movimentos sociais organizados, associações comunitárias e organizações não-governamentais.

Para a execução da proposta de trabalho do projeto, foi de fundamental importância a construção coletiva dos conceitos de participação, planejamento, gestão e comunidade, bem como a reflexão sobre o temário das Políticas Públicas Territoriais e as repercussões do Planejamento e da Gestão Comunitária. Para tanto, mesmo tendo um caráter prático, foi necessário trabalhar com o que chamamos "nivelamento conceitual", em que os conceitos supracitados são discutidos a partir de algumas obras como Freire (1987); Jacobi (2000), Melo Neto (1999), Boff(1986) e Thiollent (2005).

Tivemos como objetivos da proposta de intervenção: a) discutir os conceitos fundamentais referentes à dinâmica do espaço urbano e regional; b) estudar os conceitos de participação, planejamento, gestão e comunidade; c) promover a interação entre os membros acadêmicos (discentes e docentes) e a sociedade local; d) identificar quais os possíveis aspectos da realidade local para a intervenção nos espaços comunitários do(s) município(s); e) caracterizar as principais problemáticas socioespaciais dos espaços comunitários do(s) município(s); f) aplicar metodologias e técnicas que estimulem a participação ativa dos atores sociais envolvidos; g) produzir material didático (formativo e informativo) sobre as temáticas abordadas e situações-problema encontradas no campo. 
Para a concretização das ações do projeto, desenvolvemos a perspectiva metodológica em três fases distintas, porém interligadas. São elas:

$1^{\text {a }}$ Fase: Formação geral e nivelamento conceitual e metodológico

- Apresentação do projeto didático e dos objetivos da proposta de intervenção;

- Levantamento das fontes bibliográficas relacionadas e de dados secundários preliminares;

- Construção coletiva dos conceitos de participação, planejamento, gestão e comunidade;

- Nivelamento conceitual e metodológico (espaço formativo ${ }^{3}$ );

- Socialização de experiências em atividades de planejamento e gestão comunitária;

- Discussão e aplicação simulada de metodologias e técnicas participativas de intervenção social local;

- Elaboração de plano de ação inicial e dos princípios norteadores da ação interventora.

$2^{\text {a }}$ Fase: Primeiros contatos com a realidade local

- Apresentação do projeto didático e dos objetivos da proposta de intervenção à sociedade local;

- Definição dos grupos sociais para a realização dos trabalhos de base comunitária (sociedade civil e sociedade política);

- Sensibilização e mobilização da sociedade dos grupos sociais;

- Apreensão e prática de dinâmicas de envolvimento entre os membros da atividade e comunitários;

- Levantamento dos sonhos (o futuro desejado);

- Reconhecimento "cartográfico" / produção de croquis temáticos;

- Caminhada de reconhecimento: "O Olho do Dono";

- Aplicação e sistematização de pesquisa de campo exploratória (caracterização socioespacial), por meio da aplicação de formulários investigativos e de entrevistas semi-abertas aos membros da atividade e comunitários.

\footnotetext{
${ }^{3}$ Este espaço ocorreu durante todo o semestre letivo a partir da perspectiva ação-reflexão-ação sobre a realidade social em estudo e intervenção. 
$3^{\mathrm{a}}$ Fase: Estudo da realidade e intervenção produtiva

- Seminários comunitários e "rodas de conversa" temáticas, por segmento social/núcleo, para realizar: a) Estudo da realidade e identificação das principais problemáticas (problematização e priorização dos problemas) de cada núcleo comunitário ${ }^{4}$; b) elaboração das propostas de solução (ações de conquista para o futuro) para os núcleos;

- Elaboração de subprojetos de intervenção temática (parceria com a comunidade);

- Aplicação dos subprojetos temáticos.

Como procedimentos avaliativos, citamos:

- Relatório parcial I: sobre a atividade formativa e a aplicação simulada de situaçõesproblema e metodologia participativa;

- Relatórios de campo orientados: a) sistematização e análise da pesquisa de campo exploratória; b) da síntese dos seminários comunitários e das "rodas de conversa" temáticas;

- Produção textual: um relato de experiência acerca da atividade prática desenvolvida.

\section{CONSIDERAÇÕES FINAIS}

Podemos assinalar, como primeira observação, que o corpo discente que atua no projeto perfaz uma diversidade no que se refere à experiência de vida acadêmica. O projeto "Nos caminhos da Geografia" contou com alunos de vários períodos, o que nos coloca diante de um desafio ainda mais inquietante: o nivelamento conceitual e metodológico, haja vista a diversidade de experiências dos sujeitos da aprendizagem.

Nas oportunidades em que o projeto foi executado, observamos um envolvimento dos agentes internos da sociedade, particularmente nos espaços escolares, na organização do evento de culminância. Os alunos de licenciatura do curso de Geografia depararam-se, pela primeira vez, com o ambiente escolar antes do início do Estágio Supervisionado, o que consideramos importante para sua a formação.

As expectativas no desenvolvimento do projeto em outros momentos são boas. A princípio, os alunos têm mostrado assiduidade e envolvimento nas atividades desenvolvidas nas fases do projeto. Esperamos que, quando partirmos para a segunda e terceira fases do projeto, possamos firmar parcerias com os municípios-campo do projeto que passam por um processo de transição e reestruturação administrativa nas prefeituras, tendo em vista o ano eleitoral. Assim, aguardamos as primeiras respostas dos gestores dos municípios de Pau dos Ferros e Encanto.

\footnotetext{
${ }^{4} \mathrm{O}$ núcleo comunitário correspondeu à definição de grupo social local (bairro, grupo de jovens, grupo de mulheres, associação de moradores etc.). Para tanto, os segmentos sociais da sociedade civil e política contribuíram, sobremaneira, para a definição destes núcleos.
} 
Para tanto, esperamos atingir os objetivos propostos no plano de trabalho do projeto, principalmente seguindo o foco da promoção da interação entre os membros acadêmicos (discentes e docentes) e a sociedade local, a partir da caracterização das problemáticas socioespaciais dos espaços comunitários nos municípios e da participação dos atores sociais envolvidos no projeto.

\section{REFERÊNCIAS}

BOFF, C. Como trabalhar com o povo. Rio de Janeiro: Vozes, 1986.

BRASIL. Lei de Diretrizes e Bases da Educação Nacional. Lei n 9.394, de 20 de dezembro de 1996. Estabelece as diretrizes e bases da educação nacional. Brasília, DF, 1996.

FREIRE, P. Pedagogia do oprimido. Rio de Janeiro: Paz e Terra, 1987.

FURTADO, J. R.; FURTADO, E. D. P. A Intervenção Participativa dos Atores - INPA: uma metodologia de capacitação para o desenvolvimento sustentável. Brasília: Instituto Interamericano de Cooperação para a Agricultura, 2000.

JACOBI, P. R. Educação, ampliação da cidadania e participação. Revista Educação e Pesquisa, São Paulo, v. 26, n.2, jul.-dez. 2000.

MELO NETO, J. F. de. Educação popular: uma ontologia. In: SCOCUGLIA, A C.; MELO NETO, J. F. de. (Orgs.). Educação popular: outros caminhos. João Pessoa: Editora Universitária / UFPB, 1999.

PPC. Projeto Pedagógico do Curso de Geografia. Universidade do Estado do Rio Grande do Norte, Campus Avançado Prof ${ }^{a}$ Maria Elisa de Albuquerque Maia, Pau dos Ferros, RN, out., 2007.

SANTOS, M. Técnica, espaço, tempo: globalização e meio técnico-científico-informacional. 5. ed. São Paulo: EDUSP, 2008.

THIOLlENT, M. J. M. Metodologia da pesquisa-ação. 14. ed. São Paulo: Cortez, 2005.

Submetido em 7 de fevereiro de 2012.

Aprovado em 27 de junho de 2012 